\title{
A summary of special section: regional environmental oceanography in the South China Sea and its adjacent areas (REO-SCS)
}

\author{
Jianyu Hu $\cdot$ Jiayi Pan $\cdot$ Xinyu Guo $\cdot$ \\ Quanan Zheng
}

Published online: 28 October 2011

(C) The Oceanographic Society of Japan and Springer 2011

The South China Sea (SCS) is an important marginal sea in the western Pacific Ocean, surrounded by 9 countries: Brunei, Cambodia, China, Indonesia, Malaysia, the Philippines, Singapore, Thailand, and Vietnam. Since ancient times, the SCS has served as a convenient navigation waterway for the Southeast Asian nations to communicate with each other and with nations of the outside world. Up to now, the SCS has been one of the busiest waterways in the world because of the weight and high growth rate of the region in the world economy and trade (Zheng et al. 2006). It is an inexorable trend, therefore, for the oceanographers from surrounding countries to pay more and more attention to the research of regional environmental oceanography in the SCS and its adjacent areas.

The special section "Regional Environmental Oceanography in the South China Sea and Its Adjacent Areas (REO-SCS)," which aims to deliver the latest research results to the readers, appears in two issues, 4 and 6 , Volume 67, Journal of Oceanography. The special section

\footnotetext{
J. $\mathrm{Hu}(\bowtie)$

State Key Laboratory of Marine Environmental Science, Xiamen University, Xiamen, Fujian 361005, China e-mail: hujy@xmu.edu.cn

J. Pan

Institute of Space and Earth Information Science, The Chinese University of Hong Kong, Shatin, N.T., Hong Kong, China

X. Guo

Center for Marine Environmental Studies, Ehime University,

2-5 Bunkyo-Cho, Matsuyama 790-8577, Japan

Q. Zheng

Department of Atmospheric and Oceanic Science,

University of Maryland, College Park, MD 20742, USA
}

includes 11 original papers and an introduction paper $(\mathrm{Hu}$ et al. 2011). The key points are summarized as follows.

For the mesoscale dynamics studies, Zheng et al. (2011) analyze the interaction of nonlinear Rossby eddies with the Kuroshio at the Luzon Strait using the satellite altimeter sea level data from 1993 to 2008, indicating that the eddies with a radius larger than $150 \mathrm{~km}$ are strong enough to significantly alter the Kuroshio path and are able to modify the local circulation pattern. Chen et al. (2011a) extend the Korteweg-de Vries equation to the Benjamin-Ono equation and determine the internal solitary wave amplitude in the SCS deep basin west of the Luzon Strait from satellite and in situ measurements.

There are two papers focused on studying near-inertial oscillation (NIO) in the SCS. Sun et al. (2011a) observe an NIO burst event in the western SCS by an upward-looking mooring acoustic Doppler current profiler (ADCP) in summer 2004 and reveal that typhoon "Chanchu" is a major mechanism to trigger the NIO burst event. Sun et al. (2011b) detect strong NIO from observations of three ADCP moorings in the continental shelf of the northern SCS in July 2008 and find that the NIOs are characterized by red-shifted frequencies.

There are four papers related to the current, upwelling, or water mass in the Taiwan Strait and in the Beibu Gulf. Hong et al. (2011) analyze the observational data and numerical model results and confirm the two-pronged northward flow in the southern Taiwan Strait in summer. Qiu et al. (2011) analyze the near surface circulation in the Taiwan Strait using 110 satellite-tracked surface drifters from 1989 to 2007, showing that almost all winter drifters that enter the Taiwan Strait eventually move southward. Using a nested circulation model based on the Princeton Ocean Model, Jiang et al. (2011) investigate the characteristics and mechanisms of the Southwest upwelling and 
the Taiwan Bank upwelling (Hu et al. 2003) in the southern Taiwan Strait. Chen et al. (2011b) present the comprehensive analysis of water mass in the eastern Beibu Gulf after applying the hierarchical clustering method to the observations of temperature, salinity, dissolved oxygen, alkalinity, nitrite, reactive silicate, and chlorophyll $a$.

Satellite data are applied for the studies on thermal variability, the shallow water depth retrieval, and the coastal environment monitoring. Lin et al. (2011) investigate the thermal variability in the SCS and its relationship to the western Pacific warm pool using long-term sea surface temperature data derived from satellite and in situ measurements. Fan et al. (2011) develop a method for shallow water depth retrieval from satellite synthetic aperture radar (SAR) images. Zhao et al. (2011) apply satellite synthetic aperture radar interferometry (InSAR) for detecting ground deformation of a large size coastal engineering project, the International Airport of Hong Kong.

We believe, therefore, that the special section REO-SCS serves as a platform for the community to exchange and share their ideas and results, and plays an important role in promoting the research of regional environmental oceanography in the SCS.

The editorial work of this special section is supported by the Natural Science Foundation of China through project 40976013 (for $\mathrm{Hu}$ ), partially by the US National Science Foundation Program AGS-1061998 (for Zheng), by the direct grant of the Chinese University of Hong Kong (for Pan), and by Global COE Program from the Japanese Ministry of Education, Culture, Sports, Science and Technology (for Guo). We, the guest editors of the special section, sincerely thank the dedicated work of all the reviewers, and appreciate the extensive and sustained efforts of Profs. Toshiro Saino and Toshiyuki Hibiya, Editors-in-Chief of Journal of Oceanography, and Springer Japan. Without their perseverance and guidance, the special section would not be possible.

\section{References}

Chen GY, Su F-C, Wang C-M, Liu C-T, Tseng R-S (2011a) Derivation of internal solitary wave amplitude in the South
China Sea deep basin from satellite images. J Oceanogr 67(6). doi:10.1007/s10872-011-0073-9

Chen SL, Li Y, Hu JY, Zheng AR, Huang LF, Lin YS (2011b) Multiparameter cluster analysis of seasonal variation of water masses in the eastern Beibu Gulf. J Oceanogr 67(6). doi:10. 1007/s10872-011-0071-y

Fan KG, Huang WG, Lin H, Pan JY, Fu B, Gu YZ (2011) Shallow water depth retrieval from space-borne SAR imagery. J Oceanogr 67(4):405-413. doi:10.1007/s10872-011-0037-0

Hong HS, Chen C-TA, Jiang YW, Lou J-Y, Chen ZZ, Zhu J (2011) Source water of two-pronged northward flow in the southern Taiwan Strait in summer. J Oceanogr 67(4):385-393. doi:10. 1007/s10872-011-0036-1

Hu JY, Kawamura H, Hong HS, Pan WR (2003) A review of research on the upwelling in the Taiwan Strait. Bull Marine Sci 73(3): 605-628

Hu JY, Pan JY, Guo XY, Zheng QA (2011) Introduction to the special section on regional environmental oceanography in the South China Sea and its adjacent areas (REO-SCS). J Oceanogr 67(4):359-363. doi:10.1007/s10872-011-0063-y

Jiang YW, Chai F, Wan ZW, Zhang X, Hong HS (2011) Characteristics and mechanisms of the upwelling in the southern Taiwan Strait: a three-dimensional numerical model study. J Oceanogr 67(6). doi:10.1007/s10872-011-0080-X

Lin C-Y, Ho C-R, Zheng QA, Huang S-J, Kuo N-J (2011) Variability of sea surface temperature and warm pool area in the South China Sea and its relationship to the western Pacific warm pool. J Oceanogr 67(6). doi:10.1007/s10872-011-0072-X

Qiu Y, Li L, Chen C-TA, Guo XG, Jing CS (2011) Currents in the Taiwan Strait as observed by surface drifters. J Oceanogr 67(4):395-404. doi:10.1007/s10872-011-0033-4

Sun L, Zheng QA, Wang DX, Hu JY, Tai C-K, Sun ZY (2011a) A case study of near inertial oscillation in the South China Sea using mooring observations and satellite altimeter data. J Oceanogr 67(6). doi:10.1007/s10872-011-0081-9

Sun ZY, Hu JY, Zheng QA, Li CY (2011b) Strong near-inertial oscillations in geostrophic shear in the northern South China Sea. J Oceanogr 67(4):377-384. doi:10.1007/s10872-011-0038-Z

Zhao Q, Lin H, Gao W, Zebker HA, Chen A, Yeung K (2011) InSAR detection of residual settlement of an ocean reclamation engineering project: a case study of Hong Kong International Airport. J Oceanogr 67(4):415-426. doi:10.1007/s10872-0110034-3

Zheng QA, Fang GH, Song YT (2006) Introduction to special section: dynamic processes and circulation in Yellow Sea, East China Sea, and South China Sea. J Geophys Res 111:C11S01. doi: 10.1029/2005JC003261

Zheng QA, Tai C-K, Hu JY, Lin HY, Zhang R-H, Su F-C, Yang XF (2011) Satellite altimeter observations of nonlinear Rossby eddy-Kuroshio interaction at the Luzon Strait. J Oceanogr 67(4):365-376. doi:10.1007/s10872-011-0035-2 